\title{
Simultaneous two-dimensional measurement of fuel-air ratio and temperature in a direct-injection spark-ignition engine using a new tracer-pair laser-induced fluorescence technique
}

International I of Engine Research 2016, Vol. 17(1) 120-128 (c) IMechE 2015 Reprints and permissions: sagepub.co.uk/journalsPermissions.nav DOI: $10.1177 / 1468087415613938$ jer.sagepub.com (SAGE

\author{
Susanne Lind', Lars Zigan', Johannes Trost ${ }^{2}$, Alfred Leipertz' and \\ Stefan Will'
}

\begin{abstract}
A planar tracer laser-induced fluorescence technique using a new tracer pair is introduced and has been utilized for the simultaneous detection of the fuel-air ratio and the temperature to characterize mixture formation inside a directinjection spark-ignition engine. The new tracer pair consists of triethylamine and 3-pentanone, which are simultaneously added to the surrogate fuel isooctane. Triethylamine was used for the determination of the fuel-air ratio. The temperature distribution was evaluated with the two-line excitation laser-induced fluorescence technique using 3-pentanone. Prior to the internal combustion engine measurements, the tracer mixture was first investigated in a flow cell to demonstrate the spectral separability of the fluorescence signals and for the extension of the calibration data basis. As a first application, the tracer pair was applied inside a direct-injection spark-ignition engine operated with a split-injection scheme. For the late second injection, the fuel and temperature stratification was studied during the compression stroke. The measured temperature drop due to evaporative cooling effects was found to be about $100 \mathrm{~K}$ in the averaged data and up to $125 \mathrm{~K}$ in the single-shot measurements. The relation between fuel-rich areas and strong temperature drop can clearly be seen in the results. Furthermore, the suitability of the tracer pair to resolve cyclic variations is visualized.
\end{abstract}

\section{Keywords}

Laser-induced fluorescence, multi-parameter imaging, tracer pairs, temperature distribution, fuel-air ratio, cyclic variations

Date received: 6 May 2015; accepted: 23 September 2015

\section{Introduction}

Direct injection (DI) offers a great potential for sparkignition (SI) engines for the reduction in pollutant emissions and fuel consumption. These can be mainly achieved by the improvement of mixture formation, which determines the efficiency of combustion. The mixture formation is complex and characterized by temperature and mixture stratification. These parameters have to be controlled precisely to ensure ignitability and avoid knocking and misfire even at high exhaust gas recirculation (EGR) rates. ${ }^{1,2}$

In order to visualize mixture formation inside internal combustion (IC) engines and in particular the parameters temperature and the fuel-air ratio (FAR), planar laser-induced fluorescence (PLIF) using tracer substances with known photophysical behavior is applied in IC engines. ${ }^{3-6}$ Tracer molecules added to the air or to the non-fluorescent substitute fuel are excited by an ultraviolet (UV) laser source. The spectral shape and the

\footnotetext{
'Lehrstuhl für Technische Thermodynamik (LTT) and Erlangen Graduate School in Advanced Optical Technologies (SAOT), University of Erlangen-Nürnberg, Erlangen, Germany

${ }^{2}$ Federal-Mogul Nürnberg GmbH, Nürnberg, Germany
}

\section{Corresponding author:}

Lars Zigan, Lehrstuhl für Technische Thermodynamik (LTT) and Erlangen Graduate School in Advanced Optical Technologies (SAOT), University of Erlangen-Nürnberg, Am Weichselgarten 8, D-91058 Erlangen, Germany. Email: lars.zigan@cbi.uni-erlangen.de 
intensity of the fluorescence signal are determined by the excitation wavelength, pressure, bath gas composition and temperature. ${ }^{7}$ The applied tracers have to be selected with respect to their sensitivity to the parameter of interest. For determination of the FAR toluene, ${ }^{8}$ 1-methylnaphthalene ${ }^{9}$ or triethylamine (TEA) $)^{4,6,10,11}$ has been used as the fluorescence signal is strongly quenched by the presence of oxygen. Compared to toluene and 1-methylnaphthalene, TEA provides less sensitivity on temperature and exhaust gas composition, which could contribute to an improved measurement accuracy of FAR in engines with higher amount of recirculated exhaust gas. ${ }^{12}$ Temperature distribution was successfully evaluated using a two-color detection technique with

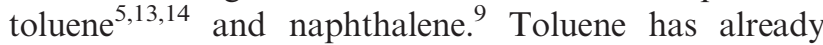
been applied in combination with particle imaging velocimetry (PIV) for high-speed thermometry in IC engines. ${ }^{15,16}$ However, nitrogen was used as ambient atmosphere to avoid strong oxygen quenching, and no information about the fuel stratification was presented. Another approach for the measurement of the temperature distribution is the two-line excitation technique with ketones such as acetone $e^{3,17,18}$ or 3-pentanone. ${ }^{19,20} \mathrm{~A}$ three-time higher sensitivity using 3-pentanone with two-line excitation can be achieved in comparison to two-color detection LIF using toluene for temperatures between 368 and $575 \mathrm{~K} .{ }^{5}$ For this reason, the two-line excitation of ketones can lead to enhanced temperature accuracy and precision.

Furthermore, two-line excitation LIF allows for the investigation of two different parameters at the same time. For example, temperature and either air or EGR concentration $^{3,21}$ were measured in an IC engine with EGR. In another application, temperature and fuel concentration were investigated in evaporating sprays in an injection chamber. ${ }^{20,22}$ However, for a complete comprehensive understanding of the mixing formation and for judging the ignitability and pollutant formation, either the FAR or the oxygen concentration must be known additionally, especially for conditions with varying ambient gas composition (e.g. for recirculation of exhaust gas).

One approach is the application of a tracer mixture consisting of two tracers for realizing simultaneous detection of FAR and temperature due to different sensitivity of the tracer's LIF signal to these parameters. Tracer mixtures were already used before to determine the mixing in isothermal flows ${ }^{23}$ or the oxygen concentration at isothermal conditions ${ }^{24,25}$ and the temperature determination at known oxygen concentration. ${ }^{26}$ Furthermore, a two-tracer technique was also employed to qualitatively investigate the evaporation of multicomponent fuels and stratification of individual components simultaneously. ${ }^{27}$ However, these tracer mixtures have not been applied for the simultaneous detection of various parameters. To determine the FAR, air concentration and temperature distribution simultaneously, a tracer mixture consisting of TEA and acetone was successfully applied in a direct-injection spark-ignition (DISI) engine with EGR. ${ }^{28}$
When using tracer combinations, interactions between the tracers may occur such as secondary excitation of tracer "two" by fluorescence emission of tracer "one." Additionally, energy transfer between the tracer molecules is possible without fluorescence emission leading to a misinterpretation of the mixing formation. Lind et al. ${ }^{28}$ could demonstrate that the individual fluorescence signal is very similar for the single tracer acetone and for the mixture of acetone and TEA. Therefore, it can be concluded that tracer interactions are negligible and this approach is valid for multiparameter imaging at IC engine conditions.

The application presented there, however, is limited to "late" mixture processes when the injected fuel (containing the FAR tracer) is already well mixed with the intake air containing the second tracer acetone for simultaneous air concentration measurement (application with EGR). For this reason, no significant temperature stratification due to evaporation cooling could be resolved with this approach during mixture formation in the suction stroke. To collect this information, the two tracers have to be mixed first before temperature and FAR could be measured simultaneously. For this purpose, a different tracer mixture approach is proposed in this article for the investigation of the early mixture formation process providing important information about local evaporative cooling and sprayinduced cyclic variation in the FAR distribution. This concept is based on the simultaneous addition of a tracer mixture of TEA and 3-pentanone to the surrogate fuel isooctane.

3 -Pentanone provides a higher boiling point $\left(102^{\circ} \mathrm{C}\right)$ than acetone $\left(56^{\circ} \mathrm{C}\right)$ being similar to that one of isooctane $\left(99^{\circ} \mathrm{C}\right)$. Furthermore, the fluorescence quantum yield of 3-pentanone is significantly larger compared to that of acetone, ${ }^{7}$ which contributes to an improved accuracy of the technique especially for mixture formation studies in IC engines. Before applying the tracer mixture in an IC engine, spectral separation of both the TEA and 3-pentanone signal have to be examined and the calibration data basis of 3-pentanone has to be extended for IC engine application. In the following, at first the fluorescence absorption and emission spectra of both tracers will be shown. These investigations were performed in a continuously scavenged calibration cell. Then, we show the application of the tracer mixture in an IC engine with DI. As an example, a split-injection scheme was adapted and the second injection in the compression stroke was studied for the simultaneous determination of FAR and temperature simultaneously. Single-shot images show the capability of the measurement technique to resolve cyclic variations in the mixing and temperature field.

\section{Measurement principle}

The laser-induced fluorescence measurements are mainly performed with lasers emitting light in the UV 
range. The laser light excites the tracer molecules to a higher energetic level. By returning to the electronic ground state, fluorescence light can be emitted. Depending on the conditions, several non-radiating processes may also occur influencing the fluorescence signal. Therefore, the fluorescence signal depends on excitation wavelength, pressure, bath gas composition and temperature. ${ }^{7}$ Following Thurber, ${ }^{29}$ the signal intensity can be described by

$$
\mathrm{S}_{\mathrm{fl}}=\eta \cdot \mathrm{E} \cdot \rho_{\mathrm{Tracer}} \cdot \sigma\left(\lambda_{\mathrm{Exc}}, \mathrm{T}\right) \cdot \phi\left(\lambda_{\mathrm{Exc}}, \mathrm{T}, \mathrm{p}, \chi_{\mathrm{i}}\right)
$$

The fluorescence signal depends on the optical efficiency factor $\eta$, the laser pulse energy $E$, the tracer partial density $\rho_{\text {Tracer }}$, the absorption cross section $\sigma\left(\lambda_{\text {Exc }}, T\right)$ depending on the excitation wavelength $\lambda_{\text {Exc }}$ and the temperature $\mathrm{T}$, and the fluorescence quantum yield $\phi\left(\lambda_{\text {Exc }}, T, p, \chi_{i}\right)$, which is a function of the excitation wavelength $\lambda_{\text {Exc }}$, temperature $T$, pressure $p$ and bath gas composition $\chi_{i}$.

For measurement of the FAR, the tracer TEA is excited with one wavelength, ${ }^{4,6}$ which is $248 \mathrm{~nm}$ in this case. Taking a homogeneous reference image at known FAR at the same position in the cycle (degree crank angle, ${ }^{\circ} \mathrm{CA}$ ) allows for the estimation of the FAR in the investigated engine cycle as the fluorescence signal depends linearly on FAR and shows only weak temperature and pressure sensitivity at the studied conditions. $^{6,12}$

The determination of temperature with ketones such as 3-pentanone requires simultaneous excitation with two wavelengths, namely, 248 and $308 \mathrm{~nm}$ in this case. Depending on the excitation wavelength, the signal shows different temperature sensitivity for $248 \mathrm{~nm}$ excitation and $308 \mathrm{~nm}$ (see also Figure 1). This effect is used for thermometry by forming a signal ratio ${ }^{17,30}$

$$
\mathrm{S}_{\mathrm{R}}=\frac{\mathrm{S}_{308}}{\mathrm{~S}_{248}}=\frac{\mathrm{E}_{308} \cdot \sigma(308, \mathrm{~T}) \cdot \phi(308, \mathrm{~T}, \mathrm{p}, \mathrm{Air})}{\mathrm{E}_{248} \cdot \sigma(248, \mathrm{~T}) \cdot \phi(248, \mathrm{~T}, \mathrm{p}, \mathrm{Air})}
$$

Calibration data of the 3-pentanone fluorescence with respect to temperature and pressure were measured in a flow cell at homogeneous conditions. ${ }^{31}$ The signal intensities of the two excitation wavelengths and the signal ratio are shown exemplarily in Figure 1 for $1 \mathrm{MPa}$ at different temperatures. The available calibration data provide values from room temperature to $548 \mathrm{~K}$ in a pressure range from 0.05 to $2 \mathrm{MPa}$, corresponding to the investigated engine operation point. The signal ratio is normalized to the signal intensity at $298 \mathrm{~K}$ and 0.1 MPa (see Figure 2). The new calibration data of 3-pentanone were extended compared to the literature data ${ }^{32}$ with respect to the pressure and temperature as the existing data are limited to $473 \mathrm{~K}$ in air atmosphere.

The temperature sensitivity is clearly visible in the signal ratio. Depending on the pressure, the signal ratio increases by a factor of 2.5 between 298 and $550 \mathrm{~K}$ at $2 \mathrm{MPa}$ or by a factor of about 7.5 at $0.05 \mathrm{MPa}$ (see Figure 2). A maximum measurement error of $3.2 \%$

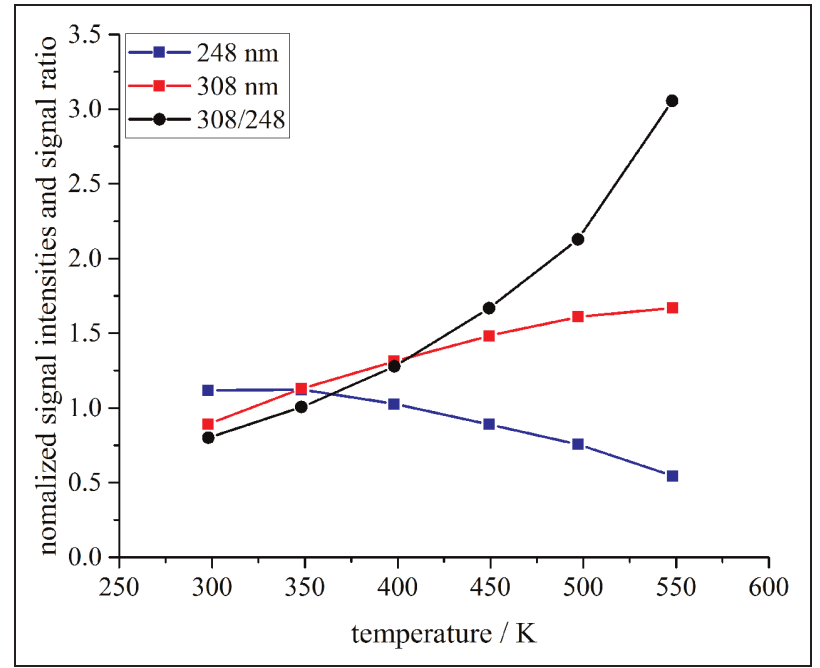

Figure I. Calibration data of 3-pentanone in air at I MPa and different temperatures; calibration data were adapted from Löffler. $^{31}$

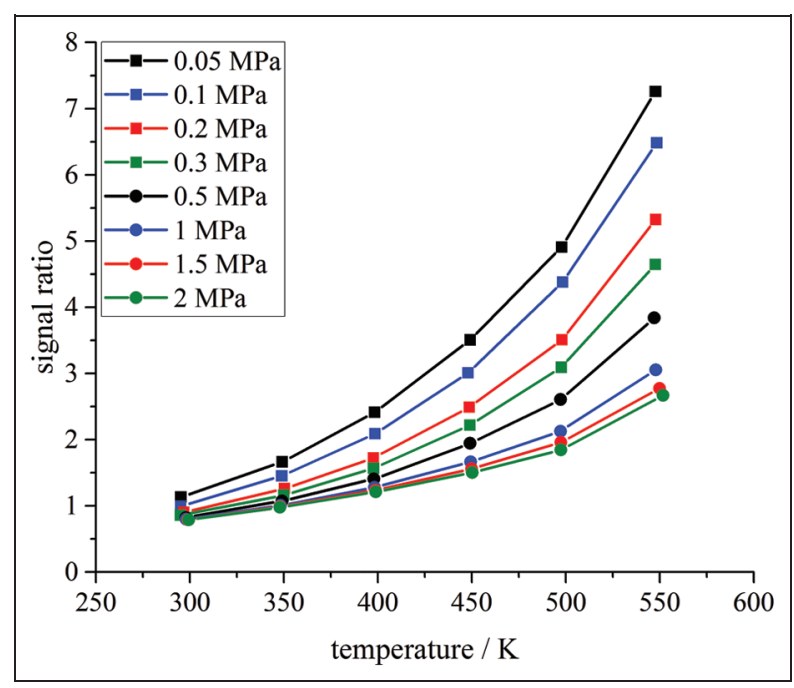

Figure 2. Calibration data of 3-pentanone in air at different temperatures and pressures; calibration data were adapted from Löffler. $^{31}$

concerning temperature estimation in the flow cell was evaluated with error propagation. A standard deviation of $\pm 7-9 \mathrm{~K}$ was determined. ${ }^{31}$ The deviation of TEALIF measurements from the lambda probe results was $4 \%$ at homogeneous stoichiometric conditions in an IC engine. $^{33}$

\section{Spectral investigation}

Using tracer mixtures requires the investigation of spectral separability and the effects of tracer interactions on individual fluorescence signals before applying the tracer combination to a technical system. To this end, the single components and tracer mixture were added to an air flow in a continuously scavenged calibration cell, 




Figure 3. Absorption and emission spectra of TEA and 3pentanone as well as emission spectrum of the tracer mixture at $423 \mathrm{~K}$ and I MPa in air; excitation at $248 \mathrm{~nm}$.

which can be operated at IC engine conditions up to $1000 \mathrm{~K}$ and $3 \mathrm{MPa}$. The continuous flow through the cell and the addition of the tracer after the heaters decrease the residence time of the tracer in the hot ambience and reduce the probability of tracer decomposition and oxidation. ${ }^{34}$ A detailed description of the calibration cell can be found elsewhere. ${ }^{35}$ The tracers were excited using a UV excimer laser at a wavelength of $248 \mathrm{~nm}$. The fluorescence emission spectra were detected with a monochromator (ACR Spectra Pro 275) and an intensified charge-coupled device (CCD) camera (Andor iStar) perpendicularly to the laser light sheet. Figure 3 shows the absorption and emission spectra of the single tracer substances as well as the emission spectra of the tracer mixture at $423 \mathrm{~K}$ and $1 \mathrm{MPa}$ in air. The tracers were mixed with a ratio of 1:30 TEA to 3-pentanone by volume to achieve similar signal intensities.

The emission spectra of both tracers show a spectral overlap between 310 and $360 \mathrm{~nm}$. Therefore, filters have to be chosen to cutoff the range of spectral overlap. For detection of the TEA signal, a filter set with transmission in the wavelength range of $270-310 \mathrm{~nm}$ was chosen. 3-Pentanone fluorescence was detected using a razor edge long-pass filter with $355 \mathrm{~nm}$ cutoff wavelength. Concerning the absorption and emission spectra, tracer interaction appears possible as the absorption spectrum of 3-pentanone covers completely the emission spectrum of TEA. This effect could potentially result in absorption of the TEA fluorescence by 3-pentanone leading to a lower fluorescence intensity of TEA and an increased fluorescence intensity of 3-pentanone.

As tracer interaction studies were already performed before $^{28}$ for TEA and another ketone (acetone) with similar photophysical behavior ${ }^{7}$ and concentration in the mixture, this study will not be repeated in this article for 3-pentanone. It appears reasonable to assume that the tracer interactions are also marginal for this tracer mixture, and that no major influences of the

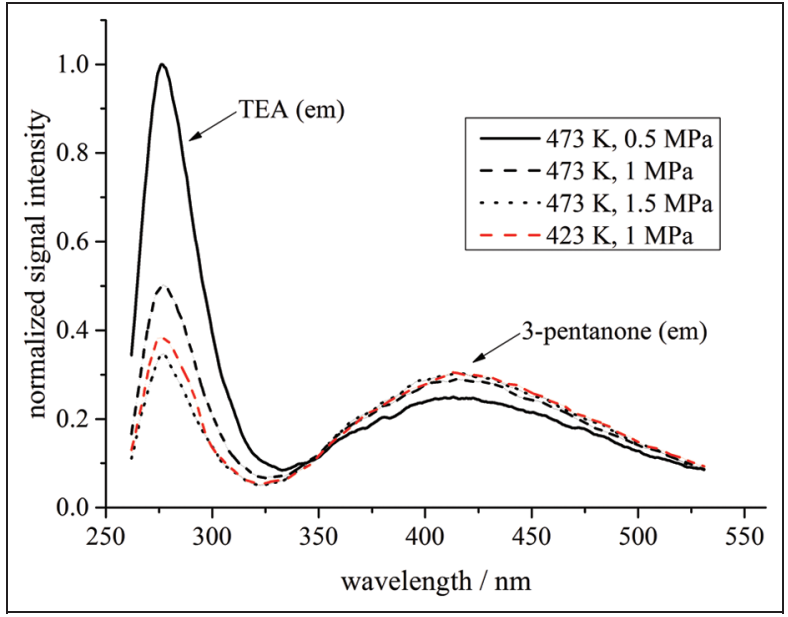

Figure 4. Emission spectra of the tracer mixture at 423 and $473 \mathrm{~K}$ at various pressures in air.

fluorescence signal of 3-pentanone are to be expected. A detailed study of tracer interaction concerning TEA fluorescence is in preparation, but first results also indicate that TEA is only weakly influenced by the presence of another ketone. ${ }^{36}$

Furthermore, it is important to ensure separability of the tracer signals at any temperature and pressure as a spectral shift of the emissions may occur. Figure 4 shows the emission spectra of the tracer mixture for temperatures of 423 and $473 \mathrm{~K}$ and pressures of $1,1.5$ and $2 \mathrm{MPa}$, respectively.

With the increase in pressure, the fluorescence intensity of TEA is decreased by the higher impact of oxygen quenching as it is a collision-dominated process. In comparison, 3-pentanone shows an inverse behavior which clarifies the low dependence of the fluorescence intensity on oxygen and a higher effect of vibrational relaxation supporting fluorescence emission. It should be noted that in this case the tracer partial density was kept constant, not the FAR as it was the case for TEA-LIF calibration in Wagner et al. ${ }^{12}$ With constant tracer partial density, the mixture becomes leaner with increasing pressure leading to reduced TEA signal. The spectra show only negligible spectral shift at different temperatures and pressures, and therefore the chosen filters can be used without increased measurement uncertainties.

\section{IC engine results}

The tracer mixture was applied in a single-cylinder optically accessible DISI engine based on a four-cylinder engine and 2.01 displacement volume. Both tracers were added to the substitute fuel isooctane with an amount of 0.25 vol. \% TEA and 20 vol. $\%$ 3-pentanone. The fuel-tracer ratio is chosen with respect to previous investigations with these tracers. ${ }^{6,20}$ The contribution of the tracer to the combustion was taken into account following the procedure proposed by Koch et al. ${ }^{4}$ by reducing the amount of fuel to maintain stoichiometry. 


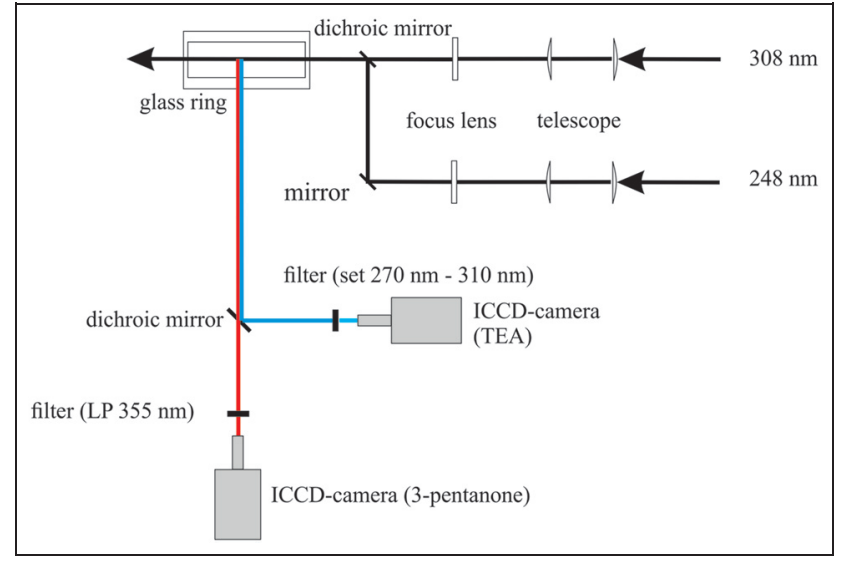

Figure 5. Optical setup for the IC engine measurements.

To allow for optical access into the combustion chamber, a fused silica glass ring was used which limited the runtime of the engine to $4 \mathrm{~min}$. TEA and 3-pentanone were excited with $248 \mathrm{~nm}$. For temperature determination with two-line excitation LIF, 3-pentanone was additionally excited with $308 \mathrm{~nm}$ with a delay of few microseconds to the previous $248 \mathrm{~nm}$ laser pulse ensuring quasi-simultaneous conditions. The lasers were operated with a repetition rate of $2 \mathrm{~Hz}$. Both laser beams were formed to light sheets and overlapped inside the cylinder. The fluorescence signals were detected with two intensified CCD cameras (PCO, Dicam PRO) equipped with the chosen filters. Furthermore, the signals were separated before by a dichroic mirror which is reflective for wavelengths below $300 \mathrm{~nm}$ and transparent for higher wavelengths. The camera for detection of the 3-pentanone signal was operated in double-shutter mode to enable quasi-simultaneous acquisition. Laser and camera were synchronized to the crankshaft position with a pulse-delay generator. The optical setup is shown schematically in Figure 5.

As a measurement example, an operating point with split-injection scheme was chosen representing a catalyst heating point. At these conditions, especially the second injection is of certain interest for studying temperature and fuel stratification since mixture inhomogeneities are significant sources of soot emissions. ${ }^{37}$ Two-thirds of the fuel are injected within the first injection at $-280{ }^{\circ} \mathrm{CA}$ after top dead center (aTDC) at an injection pressure of $6 \mathrm{MPa}$ with a solenoid multi-hole injector. The second injection is finished at $-60{ }^{\circ} \mathrm{CA}$ aTDC. The injector has a lateral position as indicated in the top left in Figure 6. The engine is operated at $0.35 \mathrm{MPa}$ indicated mean effective pressure (IMEP) and $1200 \mathrm{r} / \mathrm{min}$ with a conventional tumble and a maximum tumble ratio of 1.5 . The investigated $\mathrm{CA}$ range is $-70{ }^{\circ} \mathrm{CA}$ aTDC to $-30{ }^{\circ} \mathrm{CA}$ aTDC, which was studied in intervals of $5{ }^{\circ} \mathrm{CA}$. Ten images were taken for each CA position, which were individually analyzed and averaged afterward.

Figure 6 shows the averaged images from $-65^{\circ} \mathrm{CA}$ aTDC to $-35{ }^{\circ} \mathrm{CA}$ aTDC from top to bottom. The

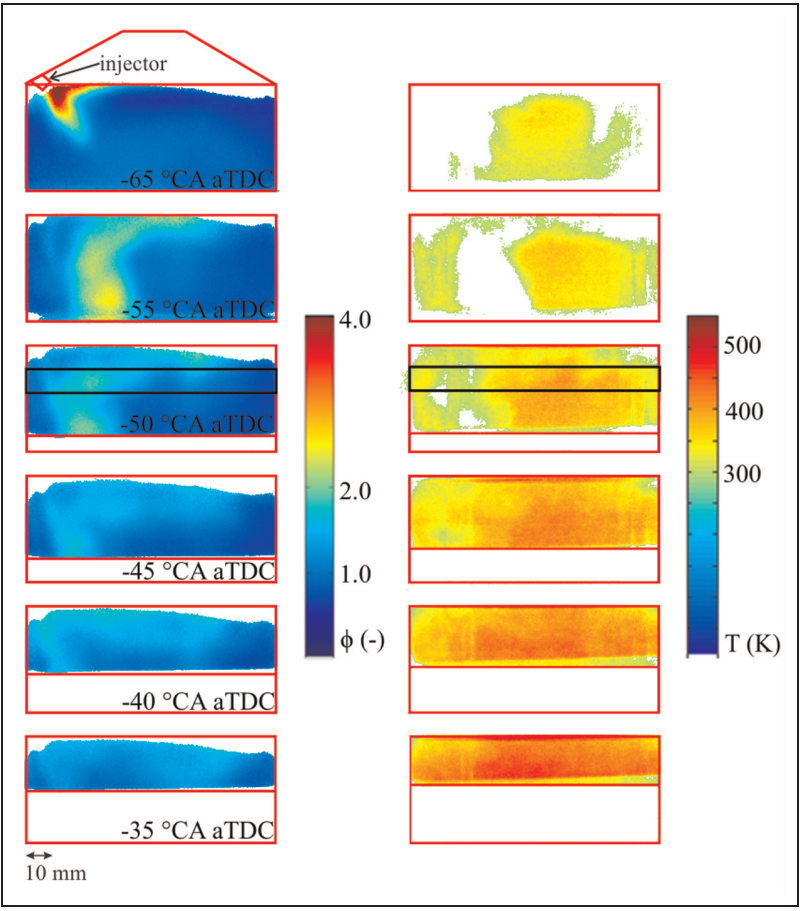

Figure 6. Averaged FAR (left) and temperature (right) between $-65^{\circ} \mathrm{CA}$ aTDC and $-35^{\circ} \mathrm{CA}$ aTDC (from top to bottom).

results from $-60{ }^{\circ} \mathrm{CA}$ aTDC are not shown as the fuel injection just finished. The FAR determined with TEALIF is shown on the left side whereas the temperature determined with two-line excitation LIF of 3-pentanone is shown on the right side. The background images without tracer were taken to correct for reflected laser light. Still, in some regions at the cylinder and piston walls, no FAR or temperature information is presented (marked with white color) as the glass ring and the piston produce strong reflections so that the signal is not evaluable. At later crankshaft positions, the piston already moves into the field of view (marked by an additional red line representing the piston head), that is, the area of the studied region is reduced. In the image of $-50{ }^{\circ} \mathrm{CA}$ aTDC, an additional black-lined rectangle is visible which marks the region of interest (ROI) for the calculation of radial FAR and temperature distributions. The ROI has a width of $92 \mathrm{~mm}$ corresponding to the bore diameter of the transparent cylinder. A height of about $9 \mathrm{~mm}$ was chosen for spatial averaging for an improved statistical representativeness of the data. The ROI is located at a position which is visible at all different CA positions.

At $-65{ }^{\circ} \mathrm{CA}$ aTDC, the beginning of the second injection is visible in the upper left part of the image. The FAR appears to be very large due to the remaining liquid fuel in the spray; under these conditions, no real quantification can be performed. The large amount of liquid fuel results in misinterpretation of the 3-pentanone LIF signal ratio taken for temperature evaluation as this is only defined for the gas phase. In these regions, extremely low temperatures would result which 


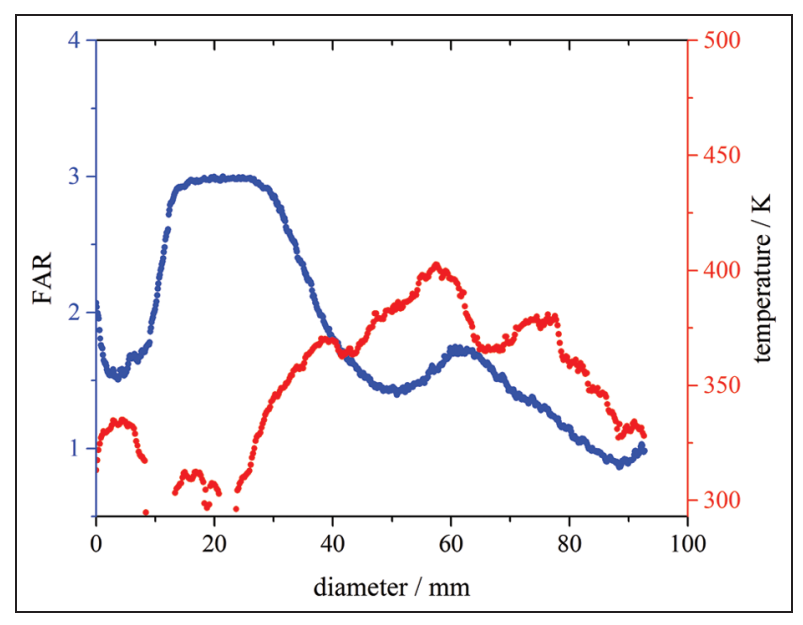

Figure 7. Averaged FAR and temperature profiles in the selected ROI (as marked with a black rectangle in Figure 6) at $-50^{\circ} \mathrm{CA}$ aTDC.

were excluded from further post-processing. Therefore, only temperatures above $293 \mathrm{~K}$ are shown in Figure 6. Due to the first injection, fluorescence signals can be detected in the surrounding of the evaporating spray; these yields an average FAR below 1 and an average temperature of about $325 \mathrm{~K}$.

The fuel injection is finished at $-60{ }^{\circ} \mathrm{CA}$ aTDC, but still at $-55{ }^{\circ} \mathrm{CA}$ liquid fuel remains in the jet, leading to non-evaluable areas in the temperature field and to areas of large FAR, respectively. At $-50{ }^{\circ} \mathrm{CA}$, the fuel is almost completely evaporated and temperature stratification can be evaluated. In the jet, the temperatures are about $300 \mathrm{~K}$ compared to about $400 \mathrm{~K}$ in its ambience. The temperature difference of about $100 \mathrm{~K}$ can be attributed to evaporative cooling, as lower temperatures match directly with fuel-rich areas. This temperature difference corresponds to the results of Trost et al. ${ }^{20}$ for an isooctane fuel spray in quiescent nitrogen atmosphere studied in an injection chamber. They reported an average temperature drop due to evaporative cooling of about $125 \mathrm{~K}$; however, the ambient conditions were even higher ( 8 bar, $673 \mathrm{~K}$ ) which could promote the evaporation and local cooling drastically. At $-45^{\circ} \mathrm{CA}$ aTDC, the temperature and fuel stratification is still visible. At later CA positions, the overall mixing temperature is increased due to the compression and fuel is distributed more homogeneously leading to reduced temperature differences inside the cylinder.

For the quantification of FAR and temperature in the cylinder, the ROI in the upper part of the cylinder (marked with the black-lined rectangle in Figure 6) was chosen. Figure 7 shows the spatial FAR and temperature distribution in the cylinder for the averaged images at $-50{ }^{\circ} \mathrm{CA}$ aTDC.

The temperature drop between 0 and $40 \mathrm{~mm}$ can be clearly attributed to evaporative cooling as the FAR is comparatively large in this area showing the inverse trend. The minimum FAR is slightly below stoichiometric mixture, which is the initial mixture from the

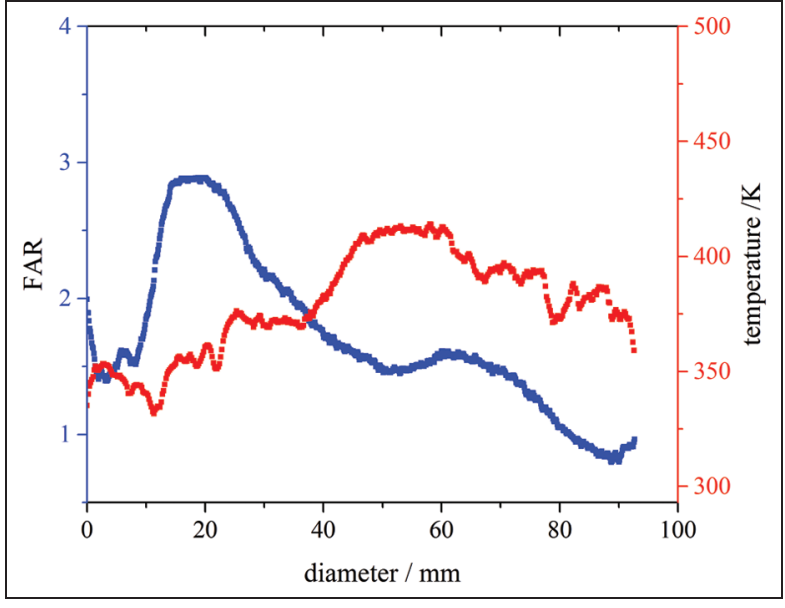

Figure 8. Averaged FAR and temperature profiles in the selected $\mathrm{ROI}$ at $-45^{\circ} \mathrm{CA}$ aTDC.

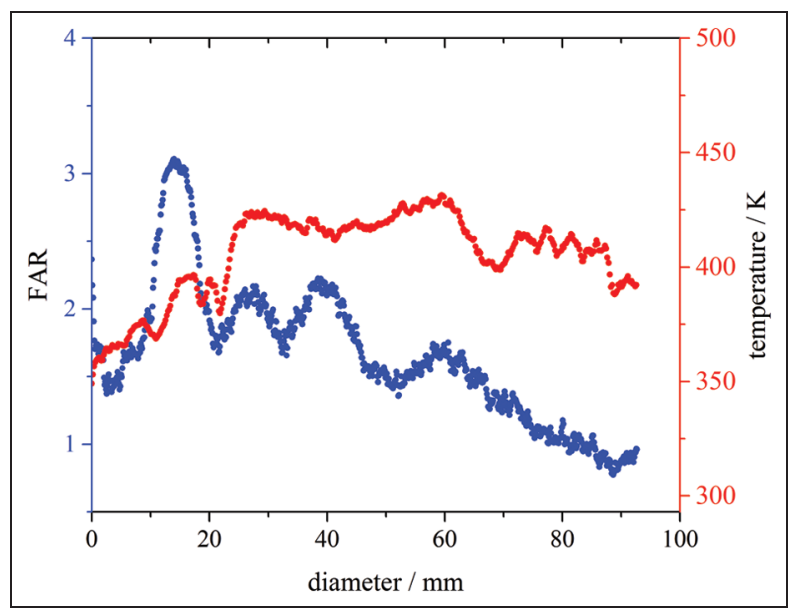

Figure 9. Averaged FAR and temperature profiles in the selected $\mathrm{ROI}$ at $-40{ }^{\circ} \mathrm{CA}$ aTDC.

first injection and appears at about $90 \mathrm{~mm}$. Within this plot, a maximum temperature difference of about $100 \mathrm{~K}$ is evaluated.

Figures 8 and 9 show the profiles of average FAR and temperature distribution at $-45{ }^{\circ} \mathrm{CA}$ aTDC and $-40{ }^{\circ} \mathrm{CA}$ aTDC, respectively. The general trend is similar to Figure 7, but the temperature difference between fuel jet and the ambience is reduced as mixing proceeds. Still, the mixture is not homogeneous and the maximum average local temperature is increased to about $430 \mathrm{~K}$ at $-40{ }^{\circ} \mathrm{CA}$ due to the compression.

Local cyclic variations in the FAR and the temperature introduced by the injection and cylinder flow have a high impact on inflammability, flame propagation and pollutant formation. To show the capability of the chosen tracer mixture concept for resolving these cyclic variations, three representative single-shot images of FAR and temperature are shown in Figures 10 and 11 for $-50{ }^{\circ} \mathrm{CA}$ aTDC and $-45^{\circ} \mathrm{CA}$ aTDC, respectively.

All images clearly show the variations in FAR and temperature of different engine cycles. Compared to 


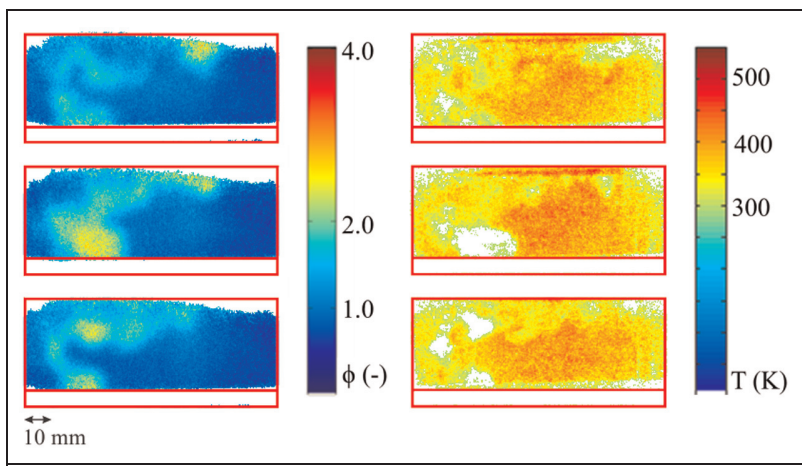

Figure 10. Single-shot images of FAR (left) and temperature (right) at $-50^{\circ} \mathrm{CA}$ aTDC.

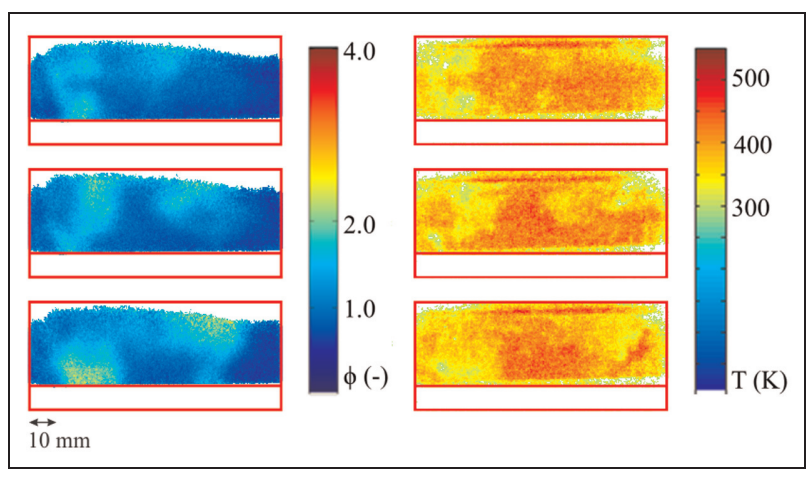

Figure II. Single-shot images of FAR (left) and temperature (right) at $-45^{\circ} \mathrm{CA}$ aTDC.

the averaged images, locally higher temperature and FAR differences are visible and the single images give a detailed insight into the turbulent flow and charge motion. Even large vortices can be visualized as well as small-scale structures representing the local turbulent mixing characteristics. In Figure 11, the FAR distribution shows a relatively homogeneous lean mixture at the right wall but strong temperature gradients in this region (especially in cycle 3 ) with a hot spot, which are probably induced by turbulent heat transfer from the piston movement and eddy formation at the cylinder wall. These effects are not visible in the average images and confirm the need for an imaging technique that is capable to resolve these cyclic phenomena especially for fundamental studies focusing on mixing and inflammation.

Additionally, for some cycles a stronger fuel jet interaction with the piston is revealed and strong temperature stratification is visible at the piston surface. This effect could contribute to higher $\mathrm{CO}$ and unburned hydrocarbon (UHC) emissions as well as soot formation for single combustion cycles, which is not predictable with the averaged data.

For further interpretation of the data, the same ROI as in Figures 7-9 was analyzed and radial temperature and FAR profiles are generated. The FAR distribution of the three shown images at $-45^{\circ} \mathrm{CA}$ aTDC is plotted

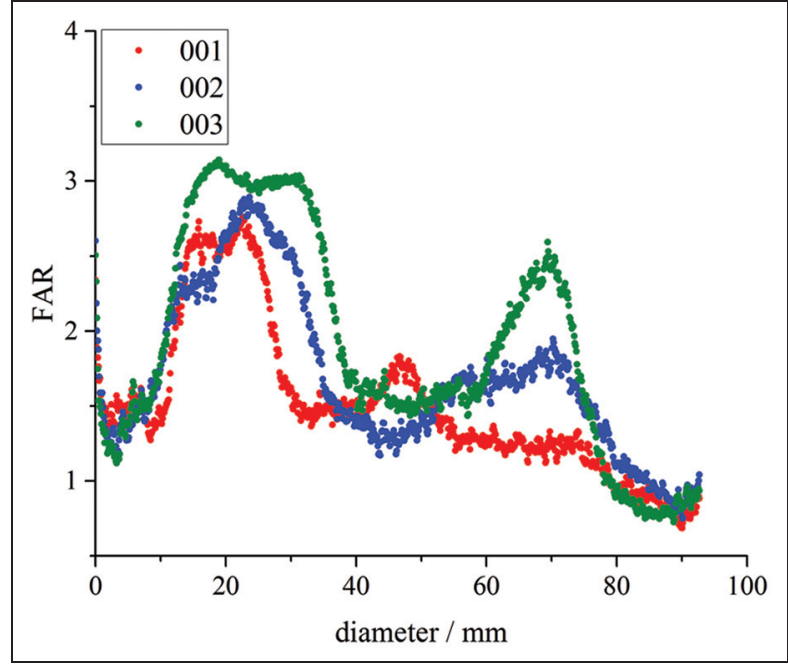

Figure 12. Single-shot FAR profiles in the selected $\mathrm{ROI}$ at $-45^{\circ} \mathrm{CA}$ aTDC for three cycles.

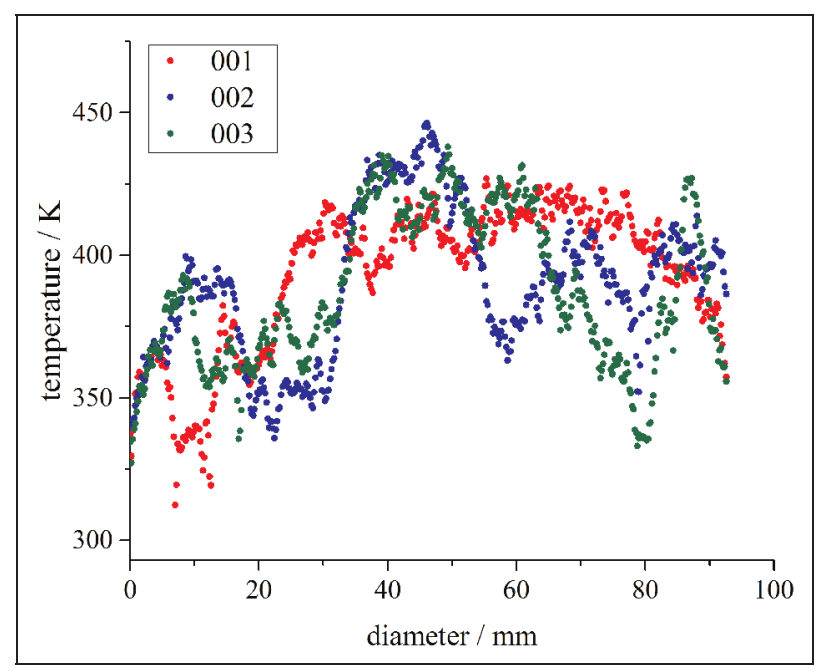

Figure 13. Single-shot temperature profiles in the selected $\mathrm{ROI}$ at $-45^{\circ} \mathrm{CA}$ aTDC for three cycles.

in Figure 12, and the temperature profiles are shown in Figure 13.

The single-shot FAR profiles always show two distinct peaks which are not that clearly visible in the average profile. The maximum temperature is about $450 \mathrm{~K}$ (cycle 2), whereas it is just about $420 \mathrm{~K}$ in the average profile. The temperature drop due to evaporation cooling is even larger for single-shot images (about $120 \mathrm{~K}$ ). For quantification of the spatial cyclic variability, the standard deviation is calculated. The results from the 10 individual images are exemplarily shown for the CA position at $-45^{\circ} \mathrm{CA}$ aTDC in Figure 14.

In general, the standard deviation of FAR is typically in the range of $0.5-1.0$ and is larger in the fuel-rich areas and less significant in lean regions. For the temperature, the standard deviation shows two major regions with strong fluctuations (about $120 \mathrm{~K}$ or even more corresponding to evaporation cooling and spatial 




Figure 14. Standard deviation of FAR (left) and temperature (right) calculated from 10 images at $-45^{\circ} \mathrm{CA}$ aTDC.

spray fluctuations from shot to shot) especially in the left part of the cylinder, that is, close to the injector. Obviously, the spray induces large vortices in the ambient gas (air), which is accelerated and leads to changed temperature fields from shot to shot.

\section{Conclusion}

A new tracer LIF concept is demonstrated using the combined application of the tracer TEA for determination of the FAR and 3-pentanone used for the simultaneous measurement of temperature by adding them to the surrogate fuel isooctane. The results show the suitability of the tracer mixture TEA-3-pentanone for the simultaneous investigation of these parameters within a plane and enabling the resolution of cyclic variations in the mixing field.

Before applying the tracer pair in an IC engine, spectral investigations have been performed. The separability of the fluorescence signals with optical filters was shown. Furthermore, uncertainties by spectral shift with varying conditions could be excluded. The calibration data basis for 3-pentanone was extended toward higher temperatures and pressures which are relevant for DISI conditions.

As example for engine measurements, the tracer mixture was applied in a DISI engine for an emissionrelevant operating point with a split-injection scheme, which is used for catalyst heating. The averaged images show temperature differences in fuel-rich areas due to evaporative cooling of about $100 \mathrm{~K}$, which are larger for single-shot images to about $120 \mathrm{~K}$. To investigate cyclic variations, single-shot images from different engine cycles were evaluated, and standard deviations were calculated for their local quantification. It could be shown that major cyclic variability of FAR and temperature distribution is introduced by fluctuations of the spray. The charge movement shows also temperature gradients at the wall in regions where no FAR gradients are visible. This observation implies that temperature gradients are probably produced by the vortex formation at the cool cylinder wall induced by the piston movement.

The visualization of cyclic variations concerning FAR and temperature gives an overall understanding for mixture formation and reveals the consequences for pollutant emissions being of major importance for emission legislation. Therefore, simultaneous multiparameter detection with tracer mixtures provides high potential for IC engine optimization with respect to mixture and pollutant formation.

\section{Acknowledgements}

We thank our colleagues T. Mederer, R. Welß and M. Wensing for supporting the engine experiments and the post-processing of the measurement data as well as for helpful discussions.

\section{Declaration of conflicting interests}

The author(s) declared no potential conflicts of interest with respect to the research, authorship and/or publication of this article.

\section{Funding}

The author(s) disclosed receipt of the following financial support for the research, authorship, and/or publication of this article: The authors gratefully acknowledge funding of the Erlangen Graduate School in Advanced Optical Technologies (SAOT) by the German Research Foundation (DFG) in the framework of the German Excellence Initiative of the German Federal and State Governments to promote science and research at German Universities.

\section{References}

1. Schumann F, Sarikoc F, Buri S, Kubach H and Spicher U. Potential of spray-guided gasoline direct injection for reduction of fuel consumption and simultaneous compliance with stricter emissions regulations. Int J Engine Res 2013; 14: 80-91.

2. Dahnz C and Spicher U. Irregular combustion in supercharged spark ignition engines-pre-ignition and other phenomena. Int J Engine Res 2010; 11: 485-498.

3. Löffler M, Beyrau F and Leipertz A. Acetone laserinduced fluorescence behavior for the simultaneous quantification of temperature and residual gas distribution in fired spark-ignition engines. Appl Optics 2010; 49: 37-49.

4. Koch P, Löffler M, Wensing M and Leipertz A. Study of the mixture formation processes inside a modern directinjection gasoline engine. Int $J$ Engine Res 2010; 11: 455-471.

5. Luong M, Zhang R, Schulz C and Sick V. Toluene laserinduced fluorescence for in-cylinder temperature imaging in internal combustion engines. Appl Phys B: Lasers $O$ 2008; 91: 669-675.

6. Blotevogel T, Hartmann M, Rottengruber $\mathrm{H}$ and Leipertz A. Tracer-based laser-induced fluorescence measurement technique for quantitative fuel/air-ratio measurements in a hydrogen internal combustion engine. Appl Optics 2008; 47: 6488-6496.

7. Schulz C and Sick V. Tracer-LIF diagnostics: quantitative measurement of fuel concentration, temperature and fuel/air ratio in practical combustion systems. Prog Energ Combust 2005; 31: 75-121.

8. Williams B, Ewart P, Wang X, Ma H, Walmsley H, Cracknell R, et al. Quantitative planar laser-induced fluorescence imaging of multi-component fuel/air mixing 
in a firing gasoline-direct-injection engine: effects of residual exhaust gas on quantitative PLIF. Combust Flame 2010; 157: 1866-1878.

9. Kaiser SA and Long MB. Quantitative planar laserinduced fluorescence of naphthalenes as fuel tracers. $P$ Combust Inst 2005; 30: 1555-1563.

10. Fröba AP, Rabenstein F, Münch KU and Leipertz A. Mixture of triethylamine (TEA) and benzene as a new seeding material for the quantitative two-dimensional laser-induced exciplex fluorescence imaging of vapor and liquid fuel inside SI engines. Combust Flame 1998; 112: 199-209.

11. Mederer $\mathrm{T}$, Wensing $\mathrm{M}$ and Leipertz $\mathrm{A}$. Investigation of the interaction of charge motion and residual gas concentration in an optically accessible SI engine. SAE technical paper 2013-01-0558, 2013.

12. Wagner V, Goldlücke J, Selig O and Leipertz A. Potential von Mehrkomponentenkraftstoff für eine quantitative Gemischbildungsanalyse mit laserinduzierter Fluoreszenz. In: Leipertz A (ed.) Engine combustion processes, VI congress, Munich, 18-19 March 2003, pp. 251-261.

13. Luong M, Koban W and Schulz C. Novel strategies for imaging temperature distribution using Toluene LIF. $J$ Phys Conf Ser 2006; 45: 133-139.

14. Kaiser SA, Schild M and Schulz C. Thermal stratification in an internal combustion engine due to wall heat transfer measured by laser-induced fluorescence. P Combust Inst 2013; 34: 2911-2919.

15. Peterson B, Baum E, Böhm B, Sick V and Dreizler A. High-speed PIV and LIF imaging of temperature stratification in an internal combustion engine. P Combust Inst 2013; 34: 3653-3660.

16. Peterson B, Baum E, Böhm B, Sick V and Dreizler A. Spray-induced temperature stratification dynamics in a gasoline direct-injection engine. $P$ Combust Inst 2015; 35: 2923-2931.

17. Thurber MC, Grisch $F$ and Hanson RK. Temperature imaging with single- and dual-wavelength acetone planar laser-induced fluorescence. Opt Lett 1997; 22: 251-253.

18. Thurber MC and Hanson RK. Simultaneous imaging of temperature and mole fraction using acetone planar laserinduced fluorescence. Exp Fluids 2001; 30: 93-101.

19. Koch JD and Hanson RK. Temperature and excitation wavelength dependencies of 3-pentanone absorption and fluorescence for PLIF applications. Appl Phys B: Lasers O 2003; 76: 319-324.

20. Trost J, Zigan L and Leipertz A. Quantitative vapor temperature imaging in DISI-sprays at elevated pressures and temperatures using two-line excitation laser-induced fluorescence. P Combust Inst 2013; 34: 3645-3652.

21. Rothamer DA, Snyder JA, Hanson RK and Steeper RR. Optimization of a tracer-based PLIF diagnostic for simultaneous imaging of EGR and temperature in IC engines. Appl Phys B: Lasers O 2010; 99: 371-384.

22. Zigan L, Trost $\mathbf{J}$ and Leipertz A. Visualisation of temperature and vapour distribution in a gasoline spray. MTZ Worldw 2014; 75: 50-55.

23. King GF, Lucht RP and Dutton JC. Quantitative dualtracer planar laser-induced fluorescence measurements of molecular mixing. Opt Lett 1997; 22: 633-635.
24. Frieden D, Sick V, Gronki J and Schulz C. Quantitative oxygen imaging in an engine. Appl Phys B: Lasers $O$ 2002; 75: 137-141.

25. Koban W, Schorr J and Schulz C. Oxygen-distribution imaging with a novel two-tracer laser-induced fluorescence technique. Appl Phys B: Lasers O 2002; 74: 111114.

26. Kakuho A, Nagamine M, Amenomori Y, Urushihara T and Itoh $\mathrm{T}$. In-cylinder temperature distribution measurement and its application to HCCI combustion. SAE technical paper 2006-01-1202, 2006.

27. Itani LM, Bruneaux G, Di Lella A and Schulz C. Twotracer LIF imaging of preferential evaporation of multicomponent gasoline fuel sprays under engine conditions. P Combust Inst 2015; 35: 2915-2922.

28. Lind S, Trost J, Zigan L, Leipertz A and Will S. Application of the tracer combination TEA/acetone for multiparameter laser-induced fluorescence measurements in IC engines with exhaust gas recirculation. P Combust Inst 2015; 35: 3783-3791.

29. Thurber MC. Acetone laser-induced fluorescence for temperature and multiparameter imaging in gaseous flows. PhD Thesis, Stanford University, Stanford, CA, 1999.

30. Grossmann F, Monkhouse PB, Ridder M, Sick V and Wolfrum J. Temperature and pressure dependences of the laser-induced fluorescence of gas-phase acetone and 3-pentanone. Appl Phys B: Lasers O 1996; 62: 249-253.

31. Löffler M. Entwicklung einer planaren Lasermesstechnik zur simultanen Temperatur- und Konzentrationsmessung bei Gemischbildungsprozessen im Ottomotor. PhD Thesis, ESYTEC-Verlag, BEV-Heft 11.5, Erlangen, 2011.

32. Modica V, Morin C and Guibert P. 3-Pentanone LIF at elevated temperatures and pressures: measurements and modeling. Appl Phys B: Lasers O 2007; 87: 193-204.

33. Koch P. Tracer-LIF-Techniken als Werkzeug zur Optimierung moderner direkteinspritzender Ottomotoren. $\mathrm{PhD}$ Thesis, ESYTEC-Verlag, BEV-Heft 10.4, Erlangen, 2010.

34. Trost J, Zigan L, Eichmann SC, Seeger T and Leipertz A. Investigation of the chemical stability of the laser-induced fluorescence tracers acetone, diethylketone, and toluene under IC engine conditions using Raman spectroscopy. Appl Optics 2013; 52: 6300-6308.

35. Trost J, Zigan L, Leipertz A, Sahoo D and Miles PC. Characterization of four potential laser-induced fluorescence tracers for diesel engine applications. Appl Optics 2013; 52: 8001-8007.

36. Mederer T, Friedrich W, Trost J, Zigan L and Wensing M. Simultaneous spatially resolved visualization of fuel/ air ratio and residual gas distribution in an optically accessible SI engine. In: Bargende $\mathbf{M}$, Wiedemann $\mathbf{J}$ and Reuss H-C (eds) 14 Internationales Stuttgarter Symposium. Wiesbaden: Springer Fachmedien Wiesbaden, 2014, pp. 349-372.

37. Storch M, Hinrichsen F, Wensing M, Will S and Zigan L. The effect of ethanol blending on mixture formation, combustion and soot emission studied in an optical DISI engine. Appl Energ 2015; 156: 783-792. 